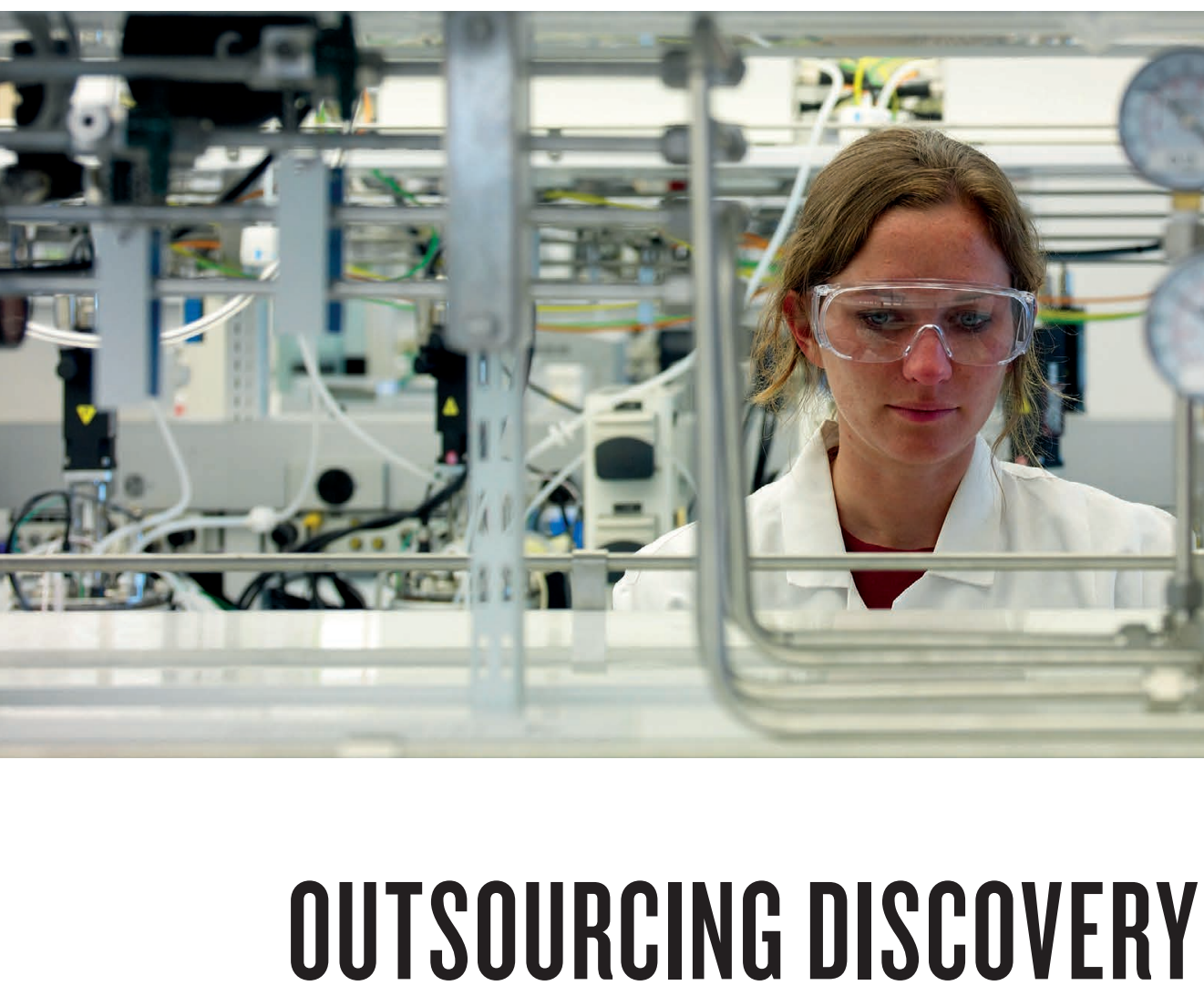

$\longrightarrow$ orporations are withdrawing from the hard slog and financially risky work of science, for more tangible and immediate gains. The demise of large corporate research laboratories has long been a source of regret, and analysts are beginning to trace the fallout. Most recently, researchers at Duke University have found that the average firm in the United States published close to a third as many papers in 2006 as they did in 1980 (S6). In the high-quality research tracked by the Nature Index, corporate institutions contribute only $2 \%$ of the share of authorship.

But innovation is a knowledge-hungry enterprise. To make up for the loss of internal scientific output, corporations are increasingly relying on the efforts of external institutions. Companies are seeking academic and government research bodies to share the burden of discovery.

Over the past five years, the number of bilateral collaborations between a corporate and an academic or government institution in the index has more than doubled, reaching 25,900 in 2016 . Close to $90 \%$ of the papers authored by a corporate institute have a co-author in either an academic or government institute. Some of the most prolific partnerships are between institutions that complement each other's strengths (S26).

These arrangements are often mutually beneficial. Companies gain access to low-cost expertise, fresh ideas and a source of highquality inputs into their product pipeline. Cash-strapped universities gain supplementary funding, and potential jobs for their graduates.

As governments and funding agencies push universities to deliver more return on their investments, academics are being squeezed into a tighter relationship with industry. Companies would do well to welcome the alliance with open arms, and relieve themselves of the growing costs of secrecy. This is especially relevant in the pharmaceutical sector where the cost of developing marketable drugs has more than tripled in 20 years (S18).

New research also suggests that academic researchers are more productive when they partner with a company (S11). There is much to be gained from corporate-academic collaboration, but the decline of scientific research within large firms could narrow the scope of innovation (S10).

\section{Smriti Mallapaty}

Senior editor, Nature Index
EDITORIAL: Catherine Armitage, Smriti Mallapaty, Stephen Pincock, Rebecca Dargie, Herb Brody, Victoria Kitchener ANALYSIS: Aaron Ballagh, Bo Wu, Willem Slijp, Alexander Scherrmann ART \& DESIGN: Alisdair Macdonald Kate Duncan, Mohamed Ashour, Ruffi Lu, Chika Takeda, Wojtek Urbanek WEB DEVELOPMENT \& DESIGN: Bob Edenbach, Olivier Lechevalier, Bart Riepe, Naomi Nakahara, Erika Suzuki DATA QUALITY: Jörn Ishikawa, Yuxin Wang, Paul Glaeser, Randell Roach, Miho Kawana, Megha Katyal PRODUCTION: Sue Gray, Karl Smart, Ian Pope, Ali Mosud, Nick Bruni MARKETING: Stacy Best Ruel, Angelica Sarne PROJECT MANAGEMENT: Rebecca Jones, Chris Gilloch, Sharon Wang SALES: Janet Cen, Mike Brunke, Ruby Han, Helen Hill, Maki Ishikawa, Stella Yan ART DIRECTOR: Kelly Buckheit Krause PUBLISHING: Nick Campbell, Richard Hughes, David Swinbanks

NATURE INDEX 2017 SCIENCE INC.

Nature Index 2017 Science Inc., a supplement to Nature, is produced by Nature Research, the flagship science portfolio of Springer Nature. This publication is based on data from the Nature Index, a Nature Research website maintained and made freely available at natureindex.com.

NATURE EDITORIAL OFFICES

The Campus, 4 Crinan Street, London N1 9XW, UK

Tel: +44 (0)2078334000

Fax: $+44(0) 2078434596 / 7$

CUSTOMER SERVICES

To advertise with the Nature Index, please visit natureindex.com/clientservices.feedback@nature.com

Copyright @ 2017 Macmillan

Publishers Limited, part of Springer Nature. All rights reserved. 